\title{
Endocannabinoid regulation of amyloid-induced neuroinflammation
}

Authors: Carmen Vázquez¹, Rosa M. Tolón ${ }^{1}, \underline{\text { M. Teresa Grande }}$, Marina Caraza $^{1,2}, \underline{\text { Marta Moreno }}{ }^{1}$, Erin C. Koester ${ }^{3}$, Borja Villaescusa ${ }^{1}$, Lourdes RuizValdepeñas $^{1}$, Francisco Javier Fernández-Sánchez ${ }^{1}$, Benjamin F. Cravatt ${ }^{4}$, $\underline{\text { Cecilia J. Hillard }}^{3}$ and Julián Romero ${ }^{1,2}$

Affiliation: 'aboratorio de Apoyo a la Investigación, Hospital Universitario Fundación Alcorcón, C/ Budapest 1, 28922, Alcorcón, Madrid, ${ }^{2}$ School of Biosciences, Universidad Francisco de Vitoria, Pozuelo de Alarcón, 28223, Madrid, Spain; ${ }^{3}$ Department of Pharmacology and Neuroscience Research Center, Medical College of Wisconsin, Milwaukee, Wisconsin, 53226, USA, and ${ }^{4}$ The Skaggs Institute for Chemical Biology and Departments of Cell Biology and Chemistry, The Scripps Research Institute, La Jolla, California, 92037, USA.

Corresponding author: J. Romero. Laboratorio de Apoyo a la Investigación. Hospital Universitario Fundación Alcorcón. 28922. Alcorcón. Madrid. Spain; School of Biosciences, Universidad Francisco de Vitoria, Pozuelo de Alarcón, 28223, Madrid, Spain. Telephone number: 34-91-6219846. Fax number: 3491-6219845. E-mail: jromerop@fhalcorcon.es; j.romero.prof@ufv.es 


\begin{abstract}
The modulation of endocannabinoid (EC) levels and the activation of cannabinoid receptors are seen as promising therapeutic strategies in a variety of diseases, including Alzheimer's disease (AD). We aimed to evaluate the effect of the pharmacological and genetic inhibiton of anandamide (AEA)degrading enzyme in a mouse model of $A D$ (5xFAD). Pharmacological inhibition of the fatty acid amide hydrolase (FAAH) had little impact on the expression of key enzymes and cytokines as well as on the cognitive impairment and plaque deposition and gliosis in 5xFAD mice. $\mathrm{CB}_{1}$ blockade exacerbated inflammation in this transgenic mouse model of $A D$. The genetic inactivation of $\mathrm{FAAH}$ led to increases in the expression of inflammatory cytokines. At the same time, FAAH-null 5xFAD mice exhibited a behavioral improvement in spatial memory that was independent of the level of anxiety and was not $\mathrm{CB}_{1}$-mediated. Finally, mice lacking $\mathrm{FAAH}$ showed diminished soluble amyloid levels, neuritic plaques and gliosis. These data reinforce the notion of a role for the endocannabinoid system in neuroinflammation and open new perspectives on the relevance of modulating endocannabinoid levels in the inflammed brain.
\end{abstract}

KEYWORDS: Endocannabinoid, amyloid, inflammation, glia. 
ABBREVIATIONS:

2-AG: 2-arachidonoylglycerol

A $\beta$ : amyloid-beta peptide

AD: Alzheimer's disease

AEA: arachidonylethanolamide, anandamide

APP: amyloid precursor protein

COX-2: cyclooxygenase-2

ECS: endocannabinoid system

FAAH: fatty acid amide hydrolase

GFAP: glial fibrillary acidic protein

lba1: lonized calcium-binding adapter molecule 1

$\underline{\text { L1b: interleukin 1-beta }}$

IL6: interleukin 6

iNOS: inducible nitric oxide synthase

5xFAD: Mice coexpressing five familial Alzheimer's disease mutations

NAEs: $\mathrm{N}$-acylethanolamines

OEA: oleoylethanolamide

PEA: palmitoylethanolamide

PS1: presenilin 1 
TNF $\alpha$ : Tumor necrosis factor - alpha 


\section{INTRODUCTION}

Neuroinflammation is a key feature shared by many neurodegenerative conditions, including Alzheimer's disease (AD). The neuroinflammatory reaction in this disease is thought to be provoked mainly by the deposition of the amyloid-beta peptide $(A \beta)$ in the form of neuritic plaques in the brain parenchyma which, together with the formation of neurofibrillary tangles of tau protein, constitute the neuropathologic hallmarks of AD (Wyss-Coray, 2006; Querfurth and LaFerla, 2010).

The role of neuroinflammation in neurodegenerative diseases is still controversial (see Cameron and Landreth, 2010 and Wyss-Coray and Rogers, 2012, for recent reviews). The predominant view indicates that inflammatory cytokines are released, mostly from glial cells, as a consequence of amyloid deposition and neuronal death, leading to a toxic millieu that aggravates the progression of the disease (Mrazk and Griffin, 2005). However, recent data support the notion of potentially beneficial effects of some cytokines that could play neurotrophic roles and dampen the damaging effects of amyloid accumulation (Shaftel et al, 2008).

The endocannabinoid (EC) system is generally viewed as a part of the neuroprotective endogenous mechanisms of the CNS and has been proposed as a target for the treatment of neuroinflammation (Mackie, 2006; Gowran et al, 2011; Chen et al, 2012 and 2013). Specifically, $\mathrm{CB}_{1}$ and $\mathrm{CB}_{2}$ agonists have 
been shown to provide neuroprotection in vivo (in terms of prevention of behavioral impairment, microglial activation, cytokine expression, glycogen synthase kinase-3 activity, superoxide dismutase 1 and 2 expression and tau hyperphosphorilation) and in vitro (microglial mitochondrial activity, morphology and cytokine production) in the context of $A D$ (Ramírez et al, 2005; Martin-Moreno et al, 2011 and 2012; Aso et al, 2012 and 2013). Similar non-receptor mediated effects of cannabinoids have also been reported (see luvone et al, 2009, for a review).

In addition, increased ECs levels are found after acute brain damage and seem to play a beneficial role against different types of insult, including trauma, ischemia and direct excitotoxicity, among others (Martinez-Orgado et al, 2007). For this reason, the increase in brain levels of ECs through the inhibition of the enzymes responsible for their degradation has been proposed as a promising therapeutic approach. For instance, recent data (Chen et al, 2012; Piro et al, 2012) have shown that pharmacological and genetic inhibition of the main enzyme responsible for the degradation of 2-AG, monoacylglycerol lipase (MGL), decrease neuroinflammation and cytokine production in a mouse model of $A D$. Furthermore, a role for 2-AG in periplaque synaptic dysfunction has been also proposed (Mulder et al, 2011).

Less is known on the consequences of enhancing anandamide (AEA) levels by inhibiting its degradation (see Fowler et al, 2010, for review). We have recently reported that astrocytes lacking FAAH activity exhibited an 
exacerbated inflammatory response that was especially evident when challenged with a proinflammatory stimulus, such as beta-amyloid (Benito et al, 2012). Furthermore, recent data have corroborated that FAAH deletion leads to a pro-inflammatory phenotype also in vivo, particularly involving microglial cells (Ativie et al, 2014; Vázquez et al, 2015). On the other hand, a deficit in AEA production has also been linked to the cognitive dysfunction in AD (Jung et al, 2011). 


\section{MATERIALS AND METHODS}

\subsection{Mice}

Mice coexpressing five familial Alzheimer's disease mutations (5xFAD) were purchased from Jackson Laboratories (Bar Harbor, ME, USA; Oakley et al, 2006). Mice with deletion of the gene for FAAH $\left(\mathrm{FAAH}^{-/-}\right.$mice, Cravatt et al, 2001) in the C57BL/6J background were mated with 5xFAD mice and backcrossed for at least 10 generations to generate paired 5xFAD and $5 x F A D / F A A H^{-/-}$littermates. Mice used in these experiments (6 months old) were housed and bred in the animal facilities of Universidad Rey Juan Carlos (Alcorcón, Madrid, Spain). This age was chosen based in previously published data showing that behavioral impairment in 5xFAD mice are first detected around this age (Oakley et al, 2006). Pilot experiments in our laboratory confirmed this observation (not shown). The experimental protocol met the European and Spanish regulations for protection of experimental animals (86/609/EEC and RD 1201/2005).

\subsection{Pharmacological treatments}

Mice received intraperitoneal injections (i.p.) of the compounds, dissolved in a mixture of dimethyl sulfoxide (DMSO):Cremophor:saline (1:1:18) for 12 consecutive days. Compounds used in this study included the FAAH inhibitor (3'-(aminocarbonyl)[1,1'-biphenyl]-3-yl)-cyclohexylcarbamate (URB597; Cayman Chemical, Ann Arbor, MI, USA; 3mg/kg) and the $\mathrm{CB}_{1}$ receptor antagonist $\quad \mathrm{N}$-(Piperidin-1-yl)-5-(4-chlorophenyl)-1-(2,4-dichlorophenyl)-4- 
methyl-1H-pyrazole-3-carboxamide hydrochloride (SR141716, SR1, kindly provided by Sanofi-Aventis; $5 \mathrm{mg} / \mathrm{kg}$ ).

\subsection{Behavioral determinations}

On day 8 of treatment with the corresponding compounds or vehicle, spatial memory acquisition was tested with the Morris water maze test (MWM), as described by Vorhees and Williams (2006), for four consecutive days, four trials per day. Briefly, mice ( $\mathrm{N}=9-17$ per group) were released into opaque water facing the tank wall from four different positions each day and allowed to swim for a maximum of 60 seconds. A hidden platform (below the water level) was placed in the same position for the whole test and both proximal and distal clues were used. Mice unable to find the platform at the end of that period of time were placed on the platform and allowed to stay on it for another 60 seconds. Then mice were placed in the maze at a new start location and the trial repeated as described. Time spent in finding the hidden platform (escape latency) was recorded with the Smart 3.0 software (Panlab, Barcelona, Spain).

In order to study a possible influence of anxiety, mice were subjected to the elevated plus maze (EPM) test (Trullas and Skolinick, 1993; Ramos, 2008) the day before the initiation of the MWM. Mice were placed at the intersection of the four arms of the EPM and allowed to freely explore the maze for 5 minutes. Tests were recorded with a camera and mice were scored for time 
spent and number of entries into the open and closed arms, center area, as well as for the head dipping. $70 \%$ ethanol solution was used to clean the maze between tests.

\subsection{Quantification of the expression of cytokines and enzymes by RT-PCR}

At the end of the treatment period, mice were sacrified by cervical dislocation and brains quickly extracted. One hemisphere was immediately frozen in isopentane and kept at $-80 \mathrm{C}$ until analysis. The other hemisphere was immersed in $4 \%$ paraformaldehyde in PBS and subsequently embedded in paraffin for histological studies.

Total RNA was isolated from frozen samples of hippocampus ( $N=9$ per group) using Tripure Isolation Reagent (Roche Diagnostics, Manheim, Germany) according to manufacturer's instructions. RNA was dissolved in RNase-free water and its concentration quantified by absorption at $260 \mathrm{~nm}$. Aliquots were subjected to $1 \%$ denaturing agarose gel electrophoresis and ethidium bromide staining to verify the quantity and quality of RNA. Single-stranded complementary DNA (cDNA) was synthesized from $1 \mu \mathrm{g}$ of total RNA using the Transcriptor First Strand cDNA Synthesis kit (AMV) (Roche). PCR primers and TaqMan probes were designed by Tib Molbiol (Berlin, Germany) as shown in Table 1. For normalization, $18 \mathrm{~S}$ primers and probe number 55 from Universal ProbeLibrary (Roche) were utilized. Gene expression was quantified using LightCycler FastStart DNA Master HybProbe (Roche) and Quantimix Easy Probes kit (Biotools, Madrid, Spain) in a LightCycler thermocycler 
(Roche). The concentration of primers and probes were $0.5 \mu \mathrm{M}$ and $0.2 \mu \mathrm{M}$ respectively. PCR assays were performed using $2 \mu \mathrm{l}$ of the cDNA reaction. All assays were carried out twice as independent PCR runs for each cDNA sample. Mean values were used for further calculation. A negative (no template) control was measured in each of the PCR runs. Standard curves were calculated for quantification purposes using five-fold serial dilutions of cDNA from mouse brain. The transcript amounts were calculated using the second derivate maximum mode of the LC-software version 4.0. The specific transcript quantities were normalized to the transcript amounts of the

reference gene 18S. All further calculations and statistical analyses were carried out with these values referred to as relative expression ratios.

\subsection{Quantification of cytokines by ELISA}

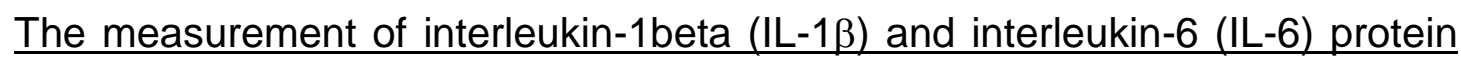
levels were made using ELISA kits purchased from Raybiotech (Norcross, GA, USA) and manufacturer's instructions were followed; protein concentration were determined in a microplate ELISA reader Multiskan EX (Thermo Scientific). Limits of detection of these assays are less than $2 \mathrm{pg} / \mathrm{ml}$ and $5 \mathrm{pg} / \mathrm{ml}$, respectively.

\subsection{Immunohistochemistry}

Paraffin-embedded tissues ( $N=3-4$ per group) were cut in $4 \mu \mathrm{m}$ slices and transferred to slides coated with Vectabond (Vector Laboratories, Burlingame, 
CA, USA). Once deparaffined and rehydrated, tissues were subjected to an antigen retrieval procedure (Benito et al, 2003) and repeatedly washed with PBS. Beta-amyloid aggregates were labelled with thioflavin staining. For immunohistochemistry, endogenous peroxidase was blocked by $50 \mathrm{~min}$ incubation at room temperature in peroxidase-blocking solution (Dako, Denmark). After several washes with PBS, tissues were incubated with primary antibody overnight at room temperature. Antibodies against markers of astrocytes, microglia and activated microglia (rabbit polyclonal anti-glial fibrillar acidic protein, GFAP; 1:1000 dilution, Dako; rabbit polyclonal anti-lba1 antibody; 1:2000 dilution, Wako, Osaka, Japan; rat anti-mouse monoclonal anti-CD68; 1:1000, BioRad, Hercules, CA, USA; respectively) were diluted in PBS containing 1\% BSA (Sigma, St. Louis, USA) and 1\% Triton $x-100$ (Sigma). After the incubation, sections were washed in PBS followed by incubation with biotinylated goat anti-rabbit antibody (1:200) for 1 hour at room temperature. Avidin-biotin complex (Vector Elite; Vector) and a diaminobenzidine (DAB) substrate-chromogen system (Dako) were used to obtain a visible reaction product. Sections were dehydrated, sealed and coverslipped. Slides were studied and photographed with an upright microscope (Nikon 90i, Nikon, Tokyo, Japan) and using a DXM1200F camera. Quantification of the slides was performed with Metamorph (Molecular Devices, Sunnyvale, CA, USA) and ImageJ (NIH, MD, USA) software.

Images were converted to 8-bit grayscale for analysis. Next, a threshold value was set (to highlight the signal corresponding to stained cells only) and the region of interest outlined by using the polygon selection tool ( $\mathrm{ROI}$ tools). The 
area occupied by thioflavin-labelled plaques, or GFAP, Iba1 or CD68 positive cells was quantified and divided by the total area of the selected region.

\subsection{Determination of brain endocannabinoid levels}

Frozen brain samples were subjected to a lipid extraction process as described by Patel et al, 2005. Tissue samples were weighed and placed into borosilicate glass culture tubes containing two $\mathrm{ml}$ of acetonitrile with 84pmol of [2H8] AEA and $186 \mathrm{pmol}$ of [2H8]2-AG. Tissue was homogenized with a glass rod and sonicated for $30 \mathrm{~min}$. Samples were incubated overnight at -20

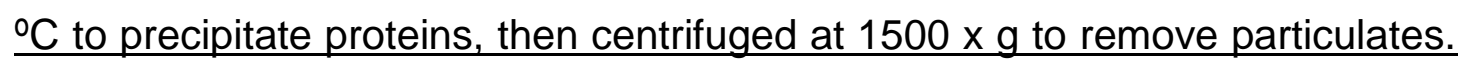
The supernatants were diluted in $300 \mu \mathrm{l}$ of methanol to recapture any lipids adhering to the glass tube, and dried again under N2 gas. Final lipid extracts were suspended in $20 \mu \mathrm{l}$ of methanol, and stored at $-80 \stackrel{\circ}{\mathrm{C}}$ until analysis. The contents of $\mathrm{N}$-acylethanolamines (NAEs; AEA, oleoylethanolamide (OEA) and palmitoylethanolamide (PEA)) as well as of 2-AG were determined in the lipid extracts using isotope-dilution, liquid chromatography-mass spectrometry as described previously (Patel et al, 2005).

\subsection{Amyloid quantification by ELISA}

The protocol used has been previously described (Aso et al, 2012). Frozen mouse brain cortices were homogenized in 4 volumes (weight:volume) of TBS extracting buffer ( $140 \mathrm{mM} \mathrm{NaCl}, 3 \mathrm{mM} \mathrm{KCl}, 25 \mathrm{mM}$ Tris, $\mathrm{pH}$ 7.4, $5 \mathrm{mM}$ EDTA and protease inhibitor cocktail; Roche). Homogenates were centrifuged at $100,000 \mathrm{~g}$ for $1 \mathrm{~h}$, and the supernatants saved as the soluble fraction for $\mathrm{A} \beta$ 
quantifications. Human ELISA kits (Invitrogen, Camarillo, CA, USA) were used for the quantification of $A \beta_{1-40}$ and $A \beta_{1-42}$ in the brain soluble fractions, following the instructions provided by the manufacturer. Levels were normalized to the total amount of protein from each individual protein.

\subsection{Quantification of amyloid-related proteins by western-blot}

Protein fractions were collected from a Tri-pure extraction of hippocampal tissues, according to manufacturer's instructions (Roche). Lysates (30 $\mu \mathrm{g} /$ /lane) were separated by SDS-PAGE and transferred onto PVDF membranes (BioRad). After blocking in TTBS (10mM Tris $\mathrm{pH} 7.5,150 \mathrm{mM}$ $\mathrm{NaCl}, 0.1 \%$ Tween 20 plus $2 \%$ bovine serum albumin) were incubated overnight at $4^{\circ} \mathrm{C}$, as appropriate, with: anti-APP (1:500, Merck Millipore, Darmstadt, Germany), anti- $\beta$-actin (1:5000, Sigma), anti-BACE1 (1:1000) and Presenilin 1 (1:1000, Abcam (Cambridge, UK). Membranes were incubated with corresponding horseradish peroxidase-conjugated secondary antibody $(1: 10,000)$ and were developed using a chemiluminescent reagent (ECL $\underline{\text { detection reagent GE Healthcare, Buckinghamshire, UK). Developed signals }}$ were recorded on X-ray film (Fujifilm) for densitometric analysis (ImageJ, $\mathrm{NIH}$, MD, USA).

\subsection{Statistical analysis}

Results are expressed as mean \pm SEM. Statistical analysis were made using student's $t$ test for comparisons between two groups, analysis of variance 
(ANOVA) with Tukey's post-test for multiple comparisons and 2-way ANOVA with Bonferroni's post-test for multiple comparisons including time course. A p value $<0.05$ was considered as statistically significant. Data were analysed with Graph Pad Prism software version 4.0a (San Diego, CA, USA). 


\section{RESULTS}

3.1. 5XFAD mice show memory impairment that is not modified by pharmacological inactivation of FAAH or by $C B_{1}$ blockade.

As has been previously reported, 5xFAD mice exhibit cognitive impairment at 6 months of age. We confirmed this observation by using a test of memory acquisition. MWM data revealed that 5xFAD mice showed an impairment in terms of escape latency (fig 1A). Treatment with URB or SR1 did not modify this effect associated to the amyloid pathology (Oakley et al, 2006).

3.2. The genetic inactivation of FAAH prevented the memory deficit in $5 x F A D$ mice without affecting anxiety and independently of $C B_{1}$ receptors.

5xFAD/FAAH ${ }^{-/}$mice showed a significant improvement in their ability to acquire spatial memory, that was more evident on the last two days of test (fig $1 \mathrm{~B})$. The treatment with the specific $\mathrm{CB}_{1}$ antagonist SR1 did not reverse this effect of the genetic deletion of FAAH (fig $1 \mathrm{C}$ ). In order to rule out a possible influence of anxiety levels on the MWM data, mice were subjected to the elevated plus maze test. Our results show an anxiolytic effect linked to the disease (as measured by the \% of time in open arms and the index of open arms avoidance), but independent of the FAAH genotype (fig $1 \mathrm{D}$ and $\mathrm{E}$ ), thus suggesting that the improvement in memory acquisition observed in $5 x \mathrm{FAD} / \mathrm{FAAH}^{-/-}$mice is independent of anxiety levels. 
3.3. Amyloid pathology leads to an increased expression of markers of neuroinflammation that is exacerbated by $C B_{1}$ receptor blockade.

The expression levels of several key inflammatory cytokines were significantly elevated as a consequence of the disease (fig $2 \mathrm{~A}$ to $\mathrm{C}$; supplementary fig 1 ). 5xFAD mice showed increased mRNA levels of IL1 $\beta$, IL6 and TNF $\alpha$ in the hippocampus, as could be expected from the inflammatory reaction triggered by amyloid deposition (Oakley et al, 2006). URB treatment did not modify the expression of IL1 $\beta$ and TNF $\alpha$, but significantly increased the levels of IL6 (fig 2 B). The treatment with SR1 increased the levels of the three cytokines, which was prevented by co-treatment with URB in the case of IL1 $\beta$ and IL6, but not TNF $\alpha$. The expression of COX-2 and iNOS (fig 2 D and E) was not affected by the disease, but was significantly increased by the treatment with SR1 (iNOS) or by the combination of URB and SR1 (COX-2). The SR1induced increase in iNOS expression was significantly reduced by cotreatment with URB (fig $2 \mathrm{E}$ ).

3.4. The genetic inactivation of FAAH potentiates inflammation in 5xFAD mice that is prevented by $\mathrm{CB}_{1}$ antagonism.

The amyloid pathology induced an inflammatory response in the hippocampus that was significantly exacerbated in $5 x F A D / F A A H^{--}$mice (fig 3; supplementary fig 1). This was especially evident for IL $1 \beta$ and IL6, but not in the case of the enzymes (fig $3 \mathrm{D}$ and $\mathrm{E}$ ), in which only a trend was measured. In addition, basal expression levels of IL6 were significantly higher in $\mathrm{FAAH}^{-1-}$ mice as compared to WTs (fig 3 B). Finally, the treatment with SR1 
dramatically reduced the overexpression of all inflammatory parameters (fig $3 A$ to $E)$.

3.5. Protein levels of cytokines are equivalent in 5xFAD and 5xFAD/FAAH ${ }^{-1-}$ $\underline{\text { mice }}$

We next analysed the levels of IL1 $\beta$ and IL6 by ELISA. Data showed that only $\underline{\mathrm{IL} 1 \beta}$ was significantly elevated in the cortex of $5 \mathrm{xFAD}$ mice, while those of IL6 remained unchanged (fig 4). In both cases, no significant differences between $\underline{\text { 5xFAD and 5xFAD/FAAH }}{ }^{-/-}$mice were observed (fig 4).

3.6. Amyloid levels and neuritic plaques are significantly decreased in $\underline{5 x F A D / F A A H^{-/-} \text {mice }}$

The analysis of hippocampal areas of 6 month old $5 x F A D$ mice revealed a high density of amyloid plaques, as could be expected from previously published data (Oakley et al, 2006; fig 5 A). We found a significant decrease of neuritic plaques in $5 \times \mathrm{FAD} / \mathrm{FAAH}^{-/-}$mice as compared to $5 \times \mathrm{FAD}$ mice (fig 5 $\underline{A}$ and $B)$. We next quantified the brain levels of the two main amyloid species that are responsible for plaque formation $\left(A \beta_{1-40}\right.$ and $\left.A \beta_{1-42}\right)$ by ELISA. We found a dramatic decrease of both amyloid peptides in FAAH-null mice as compared to WT mice (fig $5 \mathrm{C}$ and D), with decreases of more than $50 \%$. 
We next determined whether the observed decrease in amyloid levels and neuritic plaques could be due to changes in several of the proteins involved in amyloid production. Thus, we quantified the levels of APP, BACE-1 and PSN1 in homogenates obtained from WT, $\mathrm{FAAH}^{-/}, 5 \mathrm{xFAD}$ and $5 \mathrm{xFAD} / \mathrm{FAAH} \mathrm{H}^{-/}$mice (fig 6). Our results show that only APP levels were significantly decreased as a consequence of FAAH genetic inactivation (fig 6 A).

3.8. Gliosis is decreased in mice lacking FAAH but microglial cells exhibit increased activation.

The analysis of hippocampal tissue sections of $5 \mathrm{xFAD}$ and $5 \mathrm{xFAD} / \mathrm{FAAH}^{-1}$ mice showed a significant reduction in plaque-associated astro- and microgliosis by using GFAP and Iba1 as markers (fig $7 \mathrm{~A}$ and $\mathrm{B}$, and $\mathrm{C}$ and $\mathrm{D}$, respectively). Treatment with URB or SR1 did not modify any of these parameters in 5xFAD or 5xFAD/FAAH ${ }^{-/}$mice (not shown). We also analysed the activational state of microglial cells by labelling with CD68, a phenotypic marker that is known to be up-regulated in activated microglia (Matsumura et al, 2015). Our results show that, contrary to the observed decrease in the total number of microglial cells (fig $7 \mathrm{C}$ and D), levels of activated cells were similar in both 5xFAD and 5xFAD/FAAH ${ }^{-/}$mice (fig $7 \mathrm{E}$ and $\mathrm{F}$ ).

3.9. Endocannabinoid levels increase as a consequence of the inactivation of FAAH but are not affected by amyloid pathology 
We determined the brain levels of the main $N$-acylethanolamines that are substrates for FAAH as well as those of 2-AG, an endocannabinoid that is metabolized by a different enzyme (MGL). We found that the pharmacological (i.e. URB-treated) as well as the genetic inactivation of FAAH led to significant increases of AEA, PEA and OEA brain levels, without affecting those of 2-AG (fig 8). These data are confirmative of the inactivation of FAAH in our experimental conditions and the subsequent increase of EC levels. It is important to note that no differences in the levels of ECs were observed between WT and 5xFAD mice (fig 8). 


\section{DISCUSSION}

We here show that i) the enhancement of the EC tone by genetically inhibiting

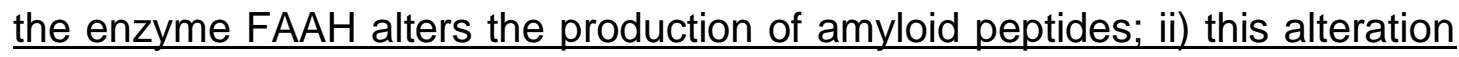
includes significant decreases in the amount of total APP, soluble $A \beta 1-40$ and A $\beta 1-42$ peptides and neuritic plaques density in the brains of $5 x \mathrm{FAD} / \mathrm{FAAH}^{-1-}$ mice; iii) micro- and astro-gliosis were also diminished in $5 \times \mathrm{FAD} / \mathrm{FAAH}{ }^{-/}$mice, but the amount of activated microglial cells was equivalent to that in 5xFAD mice; and iv) paradoxically, 5xFAD/FAAH ${ }^{-/}$mice exhibited higher levels of pro-inflammatory cytokines and, specifically, of IL1 $\beta$.

The present data confirm our previous observations of differential effect of pharmacological compared to genetic blockade of FAAH and subsequent increase in endocannabinoid levels. As previously reported for astrocytes in culture (Benito et al, 2012), as well as in vivo (Vázquez et al, 2015), this divergence is suggestive of long-term adaptations in the $\mathrm{FAAH}^{-/-}$mouse that are not obtained with a short-term pharmacological blockade of the enzyme. This may indicate that i) a maintained increase in endocannabinoids (in time and/or magnitude) is required for effects to be achieved; and ii) microglial cells seem to be particularly sensitive to these changes (Ativie et al, 2014), as observed after an acute insult to the brain parenchyma (Vázquez et al, 2015) and, as in our present report, after chronic exposure to the amyloid-induced inflammatory millieu. 
The 5xFAD mouse model is a useful tool to study the effects produced by high levels of human amyloid in the brain and by the appearance of amyloid deposits in the brain parenchyma in the form of neuritic plaques (Oakley et al, 2006). This process is an early event in the life span of 5xFAD mice, with plaques being evident as early as $2-3$ months of life. Cognitive impairment is observed at 5-6 months of age and is thought to be due to the accumulation of these pathological structures in the hippocampus and cortex, leading to inflammation and loss of functional synapses. In our hands, the behavioral impairment in these mice was corroborated (as revealed by alterations in memory and anxiety) as well as the increased neuroinflammatory state induced by amyloid accumulation.

The Morris water test relies on hippocampal-dependent spatial reference memory as well as on the inherent tendency of the subjects to escape from an aversive environment (Vorhees and Williams, 2006). We found that 5xFAD/FAAH ${ }^{-/}$mice had improved memory acquisition as compared to 5xFAD mice. This is concordance with a previous report from Varvel et al (2007), showing that $\mathrm{FAAH}^{--}$mice exhibit increased acquisition as well as extinction rates of spatial memory. The same group previously reported, however, that no differences were evident between WT and $\underline{\mathrm{FAAH}^{--}}$mice, probably due to a bias in the methodology employed (Varvel et al, 2006). This apparently paradoxical effect of FAAH genetic inactivation on memory has been previously highlighted by other authors (Panlilio et al, 2013) as $\mathrm{CB}_{1}$ agonists are known to induce amnesic effects and increased AEA levels should theoretically have a similar effect. Importantly, our present data show 
that SR1 did not prevent the improvement in spatial memory observed in 5xFAD/FAAH ${ }^{-/-}$mice, suggesting that other receptors, such as for instance PPAR $\alpha$ (Mazzola et al, 2009), might be involved in this effect. Alternatively, experimental conditions (dose, duration) could also have an influence on this lack of effect of the $\mathrm{CB}_{1}$ antagonist. Finally, it is important to note that motor function is preserved in 5xFAD mice at 6 months of age (Jawhar et al, 2012), which strongly suggests that the observed effects are due to memory impairment, as previously observed by these authors.

Also in agreement with Jawhar et al (2012), we found differences between WT and 5xFAD mice in anxiety as well as between $\mathrm{FAAH}^{-/-}$and $5 \mathrm{xFAD/FAAH}$ 1- mice, indicating that $A D$ pathology led to a decrease in the anxiety levels in both WT and FAAH ${ }^{-/}$mice. However, we did not find significant differences due to the genetic inactivation of FAAH. Methodological conditions (light, temperature, mouse strain, etc) could account for this observation, which is contrast with previously published data (Moreira et al, 2008).

On the other hand, amyloid pathology led to a significant increase in cytokine expression levels in the hippocampus of $5 x \mathrm{FAD} / \mathrm{FAAH}^{-/}$mice. This observation confirms previous in vitro (Benito et al, 2012) and in vivo (Mukhopadhyay et al, 2011; Ativie et al, 2014; Vázquez et al, 2015) evidence and underlines the profound differences that exist among ECs regarding their roles in pathological conditions of the CNS. Notably, URB did not modify the expression levels of IL1 $\beta$ and TNF $\alpha$, but significantly enhanced the levels of 
IL6, in concordance with in vitro data by Molina-Holgado et al (1998). Kerr et al (2012) have recently found a similar effect of URB in the hypothalamus of lipopolysaccharide-treated rats. Thus, our data seem confirmative of a specific effect of URB on the expression of this particular cytokine, which basal levels were also increased in $\mathrm{FAAH}^{-/-}$mice.

Currently, the most accepted opinion is that increased cytokine levels (and, more specifically, those of IL1 $\beta$ ) have a negative impact on cognitive function in AD (Mrak and Griffin, 2005; McAfoose and Baune, 2009; Rogers et al, 2011), although controversy exists on the putative significance of mutual regulation between cytokines participating in long-term potentiation and memory (Shaftel et al, 2008; Del Rey et al, 2013). It is important to note that the activity of IL $1 \beta$ is tightly related with the endocannabinoid system, as has been shown by Rossi et al (2010 and 2012) and De Chiara et al (2013). Based on these studies and, although the significance of the increase in IL1 $\beta$ expression in $5 x \mathrm{FAD} / \mathrm{FAAH}^{-/-}$mice is still unclear, we can suggest some hypotheses. First, it could be a consequence of a loss of function of TRPV1 channels, which are known to play a permissive role in the effects of IL $1 \beta$ both at the molecular and behavioral levels (Rossi et al, 2012). Furthermore, this TRPV1 loss of function could be exacerbated in $\mathrm{FAAH}^{-/}$mice due to the proinflammatory millieu, a fact that is known to potentiate the actions of AEA on these channels (Singh-Tahim et al, 2005). We can thus speculate that IL1 $\beta$ increased expression might be a compensatory response in order to surpass the loss of TRPV1 function, necessary for IL1 $\beta$ function, in mice lacking 
FAAH. Alternatively, a decrease in IL1 $\beta$ signaling efficacy could also lead to the observed increase in its expression.

It is important to highlight that 5xFAD/FAAH ${ }^{-/}$mice exhibited increase mRNA levels of $\mathrm{IL} 1 \beta$, but without a significant increase in protein levels. It is important to highlight that we did not find any decreases in cytokine levels which could be expected, at least in principle, according to the significant decrease in neuritic plaques and accompanying gliosis observed in $\underline{5 x F A / F A A H}{ }^{-/-}$mice; however, this was not the case and IL1 $\beta$ protein levels reached equivalent levels to those observed in $5 \times \mathrm{FAD}$ mice. This equivalence was also observed for CD68-positive cells, thus suggesting an exacerbated inflammatory state of microglia in 5xFAD/FAAH ${ }^{-/-}$mice, that could underlay the sustained production of IL1 $\beta$ protein (Ativie et al, 2014).

In addition, the increase in IL1 $\beta$ expression could account for the observed decrease in amyloid deposition which in turn would lead to a decrease in the gliotic response. As mentioned above, 5xFAD/FAAH ${ }^{-/}$exhibited a signifcant decrease in amyloid plaques and reduced gliosis in the hippocampus. To the best of our knowledge, these data are the first showing a FAAH-related decrease in amyloid deposition in vivo and are indicative of a beneficial effect of FAAH inactivation and confirm previous observations by Scuderi et al (2011), showing that palmitoylethanolamide (one of the main substrates for FAAH) decreases amyloid-induced gliosis. 
Elegant studies by Shaftel et al (2007) and Matousek et al (2012) using a mouse model in which IL1 $\beta$ expression can be spatially and temporally regulated, showed that an increase in IL1 $\beta$ production led to a decrease in neuritic plaque formation. This suggests that IL1 $\beta$ expression in AD could represent a beneficial response directed to counteract plaque accumulation within the brain parenchyma. This apparent contradiction might be also partially explained by previous data (Matousek et al, 2010) showing that increased prostaglandin levels (which are expected to occur in $\mathrm{FAAH}^{-/-}$mice, Kozak et al, 2002; Weber et al, 2004) prevent the cognitive impairment induced by IL1 $\beta$ overexpression. Interestingly, by using this model Matousek et al (2012) have recently shown that longer periods of neuroinflammation may result in greater plaque reduction, which could explain the discrepancy herein reported between FAAH-null and URB-treated mice.

Our data suggest a dual role for cannabinoid $\mathrm{CB}_{1}$ receptors in the context of amyloid-induced neuroinflammation. The blockade of $\mathrm{CB}_{1}$ receptors dramatically increased the expression levels of cytokines (IL1 $\beta$, IL6 and TNF $\alpha$ ) and enzymes (iNOS) which is coincident with previous literature showing an antiinflammatory effect of $\mathrm{CB}_{1}$ activation (Molina-Holgado et al, 2003; Ortega-Gutiérrez et al, 2005; Marchalant et al, 2007 and 2008). However, FAAH-null mice showed exacerbated inflammation that was reversed by SR1, which is in concordance with previous studies using different experimental paradigms (Mukhopadhyay et al, 2011; Rajesh et al, 
2012). Further studies are needed to clarify the complex interactions between the ECS and neuroinflammation.

Finally, we also found that the genetic deletion of FAAH led to significant changes in amyloid pathophysiology of 5xFAD mice. Thus, 5xFAD/FAAH ${ }^{-1-}$ mice exhibited decreased production of $A P P$, soluble $A \beta_{1-40}$ and $A \beta_{1-42}$ peptides and neuritic plaques density. In addition, the presence of activated microglial cells was similar in 5xFAD and 5xFAD/FAAH ${ }^{--}$mice. Taken together with a putative anti-amyloid role of IL1 $\beta$ (discussed above), these observations suggest that the genetic inactivation of FAAH induces multiple effects including decreased production and formation of amyloid precipitates into neuritic plaques, microglial overactivation and cyotkine production.

In summary, our data reveal a shift in the role of $\mathrm{CB}_{1}$ receptors in the context of amyloid-induced neuroinflammation that is dependent on the levels of AEA and, probably, other NAEs. The maintenance of increased levels of FAAHregulated ECs leads to a proinflammatory phenotype in vivo that may have paradoxically beneficial effects and that may help to explain previously published data regarding the effects of AEA (Clement et al, 2003).

\section{ACKNOWLEDGEMENTS}

The authors wish to thank the help of Dr. Ester Aso (Hospital de Bellvitge, Barcelona, Spain) with the determinations of soluble amyloid as well as the 
administrative work of Ms Julia Molina. Authors are indebted to Sanofi-Aventis for the kind gift of the antagonist for cannabinoid receptors. This work was supported by Ministerio de Economía y Competitividad (SAF2010/16706 and

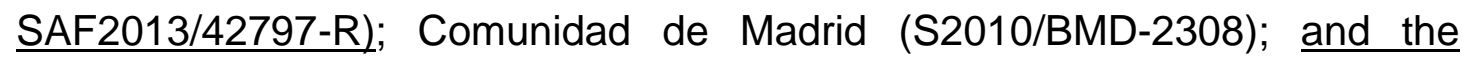
Research Component of the Advancing a Healthier Wisconsin Endowment at the Medical College of Wisconsin (CJH). C.V. is a recipient of a FPI predoctoral fellowship (BES-2011-043393) from the Spanish Ministry of Education.

\section{DISCLOSURE}

The authors declare no conflict of interest. 


\section{REFERENCES}

Aso E, Juvés S, Maldonado R, Ferrer I (2013) CB2 cannabinoid receptor agonist ameliorates Alzheimer-like phenotype in AßPP/PS1 mice. J Alzheimers Dis 35:847-58.

Aso E, Palomer E, Juvés S, Maldonado R, Muñoz FJ, Ferrer I (2012) CB1 agonist ACEA protects neurons and reduces the cognitive impairment of AßPP/PS1 mice. J Alzheimers Dis 30:439-59.

Ativie F, Albayram O, Bach K, Pradier B, Zimmer A, Bilkei-Gorzo A. 2014. Enhanced microglial activity in FAAH-/- animals. Life Sci doi: 10.1016/j.Ifs.2014.12.016.

Benito C, Nunez E, Tolon R.M, Carrier EJ, Rabano A, Hillard CJ, Romero J (2003). Cannabinoid CB2 receptors and fatty acid amide hydrolase are selectively overexpressed in neuritic plaque-associated glia in Alzheimer's disease brains. J Neurosci 23: 11136-11141.

Benito C, Tolón RM, Castillo Al, Ruiz-Valdepeñas L, Martínez-Orgado JA, Fernández-Sánchez FJ, Vázquez C, Cravatt BF, Romero J (2012) $\beta$-Amyloid exacerbates inflammation in astrocytes lacking fatty acid amide hydrolase through a mechanism involving PPAR- $\alpha$, PPAR- $y$ and TRPV1, but not $\mathrm{CB}_{1}$ or $\mathrm{CB}_{2}$ receptors. Br J Pharmacol 166:1474-89.

Cameron B, Landreth GE (2010) Inflammation, microglia, and Alzheimer's disease. Neurobiol Dis 37:503-9. 
Chen R, Zhang J, Wu Y, Wang D, Feng G, Tang YP, Teng Z, Chen C (2012) Monoacylglycerol lipase is a therapeutic target for Alzheimer's disease. Cell Rep 2:1329-1339.

Chen $R$, Zhang J, Fan $N$, Teng $Z$, Wu $Y$, Yang $H$, Tang $Y P$, Sun $H$, Song $Y$, Chen C (2013) Delta-9-THC caused synaptic and memory impaurments are mediated through COX-2 signaling. Cell 155:1154-1165.

Clement AB, Hawkins EG, Lichtman AH, Cravatt BF (2003) Increased seizure susceptibility and proconvulsant activity of anandamide in mice lacking fatty acid amide hydrolase. J Neurosci 23:3916-23.

De Chiara V, Motta C, Rossi S, Suder V, Barbieri F, Lauro D, Bernardi G, Centonze D (2013) Interleukin-1b alters the sensitivity of cannabinoid CB1 receptors controlling glutamate transmission in the striatum. Neuroscience 250:232-239.

Del Rey A, Balschun D, Wetzel W, Randolf A, Besedovsky HO (2013) A cytokine network involving brain-borne IL1b, IL1-ra, IL-18, IL-6, and TNFa operates during long-term potentiation and learning. Brain Behav and Immun 33:15-23.

Fowler CJ, Rojo ML, Rodriguez-Gaztelumendi A (2010) Modulation of the endocannabinoid system: neuroprotection or neurotoxicity? Exp Neurol 224:37-47.

Gowran A, Noonan J, Campbell VA (2011) The multiplicity of action of cannabinoids: implications for treating neurodegeneration. CNS Neurosci Ther 17:637-44. 
luvone T, Esposito G, De Filippis D, Scuderi C, Steardo L. (2009) Cannabidiol: a promising drug for neurodegenerative disorders? CNS Neurosci Ther 15:65-75.

Jawhar S, Trawicka A, Jenneckens C, Bayer TA, Wirths O (2012) Motor deficits, neuron loss, and reduced anxiety coinciding with axonal degeneration and intraneuronal $A \beta$ aggregation in the 5XFAD mouse model of Alzheimer's disease. Neurobiol Ag 33:196.e29-40.

Jung KM, Astarita G, Yasar S, Vasilevko V, Cribbs DH, Head E, Cotman CW,

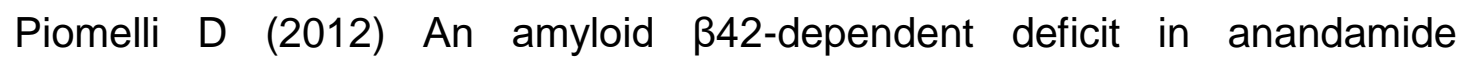
mobilization is associated with cognitive dysfunction in Alzheimer's disease. Neurobiol Ag 33:1522-32.

Kerr DM, Burke NN, Ford GK, Connor TJ, Harhen B, Egan LJ, Finn DP, Roche M (2012) Pharmacological inhibition of endocannabinoid degradation modulates the expression of inflammatory mediators in the hypothalamus following an immunological stressor. Neuroscience 204:53-63.

Kozak KR, Crews BC, Morrow JD, Wang LH, Ma YH, Weinander R, Jakobsson PJ, Marnett LJ (2002) Metabolism of the endocannabinoids, 2arachidonylglycerol and anandamide, into prostaglandin, thromboxane, and prostacyclin glycerol esters and ethanolamides. J Biol Chem 22:44877-85.

Mackie K (2006) Cannabinoid receptors as therapeutic targets. Annu Rev Pharmacol Toxicol 46:101-122.

McAfoose J, Baune BT (2009) Evidence for a cytokine model of cognitive function. Neurosci Biobehav Rev 33:355-66.

Marchalant Y, Cerbai F, Brothers HM, Wenk GL (2008) Cannabinoid receptor 
stimulation is anti-inflammatory and improves memory in old rats.

Neurobiol Ag 29:1894-901.

Marchalant Y, Rosi S, Wenk GL (2007) Anti-inflammatory property of the cannabinoid agonist WIN-55212-2 in a rodent model of chronic brain inflammation. Neuroscience 144:1516-22.

Martín-Moreno AM, Brera B, Spuch C, Carro E, García-García L, Delgado M, Pozo MA, Innamorato NG, Cuadrado A, de Ceballos ML (2012) Prolonged oral cannabinoid administration prevents neuroinflammation, lowers $\beta$-amyloid levels and improves cognitive performance in Tg APP 2576 mice. J Neuroinflammation 16;9:8.

Martín-Moreno AM, Reigada D, Ramírez BG, Mechoulam R, Innamorato N, Cuadrado A, de Ceballos ML (2011) Cannabidiol and other cannabinoids reduce microglial activation in vitro and in vivo: relevance to Alzheimer's disease. Mol Pharmacol 79:964-73.

Martínez-Orgado J, Fernández-López D, Lizasoain I, Romero J (2007) The seek of neuroprotection: introducing cannabinoids. Recent Pat CNS Drug Discov 2:131-9.

Matousek SB, Ghosh S, Shaftel SS, Kyrkanides S, Olschowka JA, O'Banion MK (2012) Chronic IL-1ß-mediated neuroinflammation mitigates amyloid pathology in a mouse model of Alzheimer's disease without inducing overt neurodegeneration. J Neuroimmune Pharmacol 7:156-64.

Matousek SB, Hein AM, Shaftel SS, Olschowka JA, Kyrkanides S, O'Banion MK (2010) Cyclooxygenase-1 mediates prostaglandin $E(2)$ elevation and contextual memory impairment in a model of sustained hippocampal 
interleukin-1beta expression. J Neurochem 114:247-58.

Matsumura A, Suzuki S, Iwahara N, Hisahara S, Kawamata J, Suzuki $H$, Yamauchi A, Takata K, Kitamura Y, Shimohama S (2015) Temporal changes of CD68 and $\alpha 7$ nicotinic acetylcholine receptor expression in microglia in Alzheimer's disease-like mouse models. J Alz Dis 44:409-423.

Mazzola C, Medalie J, Scherma M, Panlilio LV, Solinas M, Tanda G, Drago F, Cadet JL, Goldberg SR, Yasar S (2009) Fatty acid amide hydrolase (FAAH) inhibition enhances memory acquisition through activation of PPAR-alpha nuclear receptors. Learn Mem 16:332-7.

Molina-Holgado F, Molina-Holgado E, Guaza C (1998) The endogenous cannabinoid anandamide potentiates interleukin- 6 production by astrocytes infected with Theiler's murine encephalomyelitis virus by a receptor-mediated pathway. FEBS Lett 433:139-142.

Molina-Holgado F, Pinteaux E, Moore JD, Molina-Holgado E, Guaza C, Gibson RM, Rothwell NJ (2003) Endogenous interleukin-1 receptor antagonist mediates anti-inflammatory and neuroprotective actions of cannabinoids in neurons and glia. J Neurosci 23:6470-4.

Moreira FA, Kaiser N, Monory K, Lutz B (2008) Reduced anxiety-like behaviour induced by genetic and pharmacological inhibition of the endocannabinoid-degrading enzyme fatty acid amide hydrolase (FAAH) is mediated by CB1 receptors. Neuropharmacology 54:141-50.

Mrak RE, Griffin WS (2005) Glia and their cytokines in progression of neurodegeneration. Neurobiol Ag 26:349-54.

Mukhopadhyay $\mathrm{P}$, Horváth $\mathrm{B}$, Rajesh $\mathrm{M}$, Matsumoto $\mathrm{S}$, Saito $\mathrm{K}$, Bátkai $\mathrm{S}$, Patel V, Tanchian G, Gao RY, Cravatt BF, Haskó G, Pacher P (2011) Fatty 
acid amide hydrolase is a key regulator of endocannabinoid-induced myocardial tissue injury. Free Radic Biol Med 50:179-95.

Mulder J, Zilberter M, Pasquaré SJ, Alpár A, Schulte G, Ferreira SG, Köfalvi A, Martín-Moreno AM, Keimpema E, Tanila H, Watanabe M, Mackie K, Hortobágyi T, de Ceballos ML, Harkany T (2011) Molecular reorganization of endocannabinoid signalling in Alzheimer's disease. Brain 134:1041-60.

Panlilio LV, Justinova Z, Goldberg SR (2013) Inhibition of FAAH and activation of PPAR: new approaches to the treatment of cognitive dysfunction and drug addiction. Pharmacol Ther 138:84-102.

Patel S, Roelke CT, Rademacher DJ, Hillard CJ (2005) Inhibition of restraint stress-induced neural and behavioral activation by endogenous cannabinoid signaling. Eur J Neurosci 21: 1057-1069.

Oakley H, Cole SL, Logan S, Maus E, Shao P, Craft J, Guillozet-Bongaarts A, Ohno M, Disterhoft J, Van Eldik L, Berry R, Vassar R (2006) Intraneuronal beta-amyloid aggregates, neurodegeneration, and neuron loss in transgenic mice with five familial Alzheimer's disease mutations: potential factors in amyloid plaque formation. J Neurosci 26:10129-40.

Ortega-Gutiérrez S, Molina-Holgado E, Guaza C (2005) Effect of anandamide uptake inhibition in the production of nitric oxide and in the release of cytokines in astrocyte cultures. Glia 52:163-8.

Piro JR, Benjamin DI, Duerr JM, Pi Y, Gonzales C, Wood KM, Schwartz JW, Nomura DK, Samad TA (2012) A dysregulated endocannabinoid-eicosanoid network supports pathogenesis in a mouse model of Alzheimer's disease. Cell Rep 1:617-23. 
Querfurth HW and LaFerla FM (2010) Alzheimer's disease. New Eng J Med 362:329-344.

Rajesh M, Bátkai S, Kechrid M, Mukhopadhyay $P$, Lee WS, Horváth $B$, Holovac E, Cinar R, Liaudet L, Mackie K, Haskó G, Pacher P (2012) Cannabinoid 1 receptor promotes cardiac dysfunction, oxidative stress, inflammation, and fibrosis in diabetic cardiomyopathy. Diabetes 61:716-27.

Ramírez BG, Blázquez C, Gómez del Pulgar T, Guzmán M, de Ceballos ML (2005) Prevention of Alzheimer's disease pathology by cannabinoids: neuroprotection mediated by blockade of microglial activation. J Neurosci 23:1904-13.

Ramos A (2008) Animal models of anxiety: do I need multiple tests? Trends Pharmacol Sci 29:493-8.

Rogers JT, Morganti JM, Bachstetter AD, Hudson CE, Peters MM, Grimmig BA, Weeber EJ, Bickford PC, Gemma C (2011) CX3CR1 deficiency leads to impairment of hippocampal cognitive function and synaptic plasticity. $J$ Neurosci 31:16241-50.

Rossi S, De Chiara V, Musella A, Sacchetti L, Cantarella C, Castelli M, Cavasinni F, Motta C, Studer V, Bernardi G, Cravatt BF, Maccarrone M, Usiello A, Centonze D (2010) Preservation of striatal cannabinoid CB1 receptor function correlates with the antianxiety effects of fatty acid amide hydrolase inhibition. Mol Pharmacol 78:260-8.

Rossi S, Sacchetti L, Napolitano F, De Chiara V, Motta C, Studer V, Musella A, Barbieri F, Bari M, Bernardi G, Maccarrone M, Usiello A, Centonze D (2012) Interleukin-1 $\beta$ causes anxiety by interacting with the endocannabinoid 
system. J Neurosci 32:13896-905.

Scuderi C, Esposito G, Blasio A, Valenza M, Arietti P, Steardo L Jr, Carnuccio R, De Filippis D, Petrosino S, luvone T, Di Marzo V, Steardo L (2011) Palmitoylethanolamide counteracts reactive astrogliosis induced by $\beta$-amyloid peptide. J Cell Mol Med 15:2664-74.

Shaftel SS, Griffin WS, O'Banion MK (2008) The role of interleukin-1 in neuroinflammation and Alzheimer disease: an evolving perspective. J Neuroinflammation 5:7.

Shaftel SS, Kyrkanides S, Olschowka JA, Miller JN, Johnson RE, O'Banion MK (2007) Sustained hippocampal IL-1 beta overexpression mediates chronic neuroinflammation and ameliorates Alzheimer plaque pathology. J Clin Invest 117:1595-604.

Trullas R, Skolnick P (1993) Differences in fear motivated behaviors among inbred mouse strains. Psychopharmacology 111:323-31.

Varvel SA, Cravatt BF, Engram AE, Lichtman AH (2006) Fatty acid amide hydrolase (-/-) mice exhibit an increased sensitivity to the disruptive effects of anandamide or oleamide in a working memory water maze task. J Pharmacol Exp Ther 317:251-7.

Varvel SA, Wise LE, Niyuhire F, Cravatt BF, Lichtman AH (2007) Inhibition of fatty-acid amide hydrolase accelerates acquisition and extinction rates in a spatial memory task. Neuropsychopharmacology 32:1032-41.

Vázquez C, Tolón RM, Pazos MR, Moreno M, Koester EC, Cravatt BF, Hillard CJ, Romero J (2015) Endocannabinoids regulate the activity of astrocytic 
hemichannels and the microglial response against an injury: in vivo studies". Neurobiol Dis 79:41-50.

Vorhees CV, Williams MT (2006) Morris water maze: procedures for assessing spatial and related forms of learning and memory. Nat Protoc $1: 848-58$.

Weber A, Ni J, Ling KH, Acheampong A, Tang-Liu DD, Burk R, Cravatt BF, Woodward D (2004) Formation of prostamides from anandamide in FAAH knockout mice analyzed by HPLC with tandem mass spectrometry. J Lipid Res 45:757-63.

Wyss-Coray T (2006) Inflammation in Alzheimer disease: driving force, bystander or beneficial response? Nat Med 12:1005-15.

Wyss-Coray T, Rogers J (2012) Inflammation in Alzheimer disease-a brief review of the basic science and clinical literature. Cold Spring Harb Perspect Med 2:a006346. 


\section{LEGENDS TO FIGURES}

Figure 1: FAAH-null mice exhibit $\mathrm{CB}_{1}$-independent improved memory acquisition in the Morris water maze (MWM) test that is independent of anxiety levels. (A) 6 month-old 5xFAD mice exhibit memory impairment in the MWM test that reaches statistical significance in trials days 3 and 4 . URB and SR1 did not modify the impairment in memory acquisition in 5xFAD mice. (B) The genetic inactivation of $\mathrm{FAAH}\left(5 \mathrm{xFAD} / \mathrm{FAAH}^{--}\right)$prevented the memory impairment due to amyloid pathology. (C) The improvement in memory acquisition in FAAH-null mice is not mediated by $\mathrm{CB}_{1}$ receptors, as shown by the lack of effect of the treatment with SR1. (D) and (E) The effect observed in FAAH-null mice is not associated to a decrease in anxiety, as revealed by the lack of differences due to genotype in the elevated plus maze test. Note that both $5 x F A D$ and $5 x F A D / F A A H^{-/-}$mice show decreased anxiety levels as compared with their corresponding wildtypes. * $p<0.05$ (WT vs 5xFAD mice), \#<0.05 (5xFAD vs 5xFAD/FAAH ${ }^{--}$mice). Two-way ANOVA followed by Bonferroni's post hoc test.

Figure 2: CB1 signaling is anti-inflammatory in 5xFAD mice. Changes in the expression levels of inflammation-related cytokines and enzymes in the hippocampus are exacerbated by the blockade of $\mathrm{CB}_{1}$ receptors. (A) IL1 $\beta$ mRNA levels were increased as a consequence of the amyloid pathology and was not modified by the treatment with URB. $\mathrm{CB}_{1}$ blockade induced a significant increase in IL1 $\beta$ expression that was prevented by the co-treatment with URB. (B) IL6 mRNA levels were significantly elevated in 5xFAD mice and 
were exacerbated by the treatment with URB or SR1, but not by the combination of both compounds. (C) TNF $\alpha$ expression was increased in 5xFAD mice and exacerbated by SR1 and URB+SR1 treatments. (D) COX-2 expression was not increased by the amyloid pathology or by the treatment with URB or SR1, but was so by the treatment with the combination of both compounds. (E) iNOS mRNA levels were significantly increased by the treatment with SR1, an increase that was prevented by co-treatment with URB. ${ }^{*} p<0.05$. One-way ANOVA followed by Tukey's post hoc test.

Figure 3: $\mathrm{CB}_{1}$ signaling is pro-inflammatory in 5xFAD/FAAH $\mathrm{H}^{-/-}$mice. IL1 $\beta(\mathbf{A})$, IL6 (B) and TNF $\alpha(\mathbf{C})$ expression levels were increased as a consequence the amyloid pathology and were exacerbated by the genetic inactivation of $\mathrm{FAAH}$. For all three cytokines, expression was returned to basal levels by the treatment with SR1. Note that IL6 expression in $\mathrm{FAAH}^{-/-}$mice was also elevated as compared to wildtype mice. mRNA levels of COX-2 (D) and iNOS (E) were not significantly elevated due to amyloid pathology or by $\mathrm{FAAH}$ genetic inactivation. Treatment with SR1 significantly prevented the expression of both enzymes in $5 x F A D / F A A H^{--}$mice. ${ }^{*} p<0.05$. One-way ANOVA followed by Tukey's post hoc test.

Figure 4: IL1 $\beta$ and IL6 cytokine protein levels were not modified in $\underline{5 x F A D / F A A H} H^{-/-}$mice. (A) IL1 $\beta$ levels were increased as a consequence of the amyloid pathology, but were not changed in respect to the genotype. (B) IL6 
was not modified either by the pathological process or the genotype. ${ }^{*} p<0.05$ (WT vs 5xFAD mice). Two-way ANOVA followed by Bonferroni's post hoc test.

Figure 5: 5xFAD/FAAH ${ }^{-/-}$mice exhibit decreased density of amyloid plaques and diminished soluble amyloid peptides $\left(A \beta_{1-40}\right.$ and $\left.A \beta_{1-42}\right)$ in the hippocampus. (A) Representative photomicrographs of thioflavin stainings (left) of the hippocampal region (hematoxili-eosin stained, right) of a 5xFAD mouse (upper) and a 5xFAD/FAAH ${ }^{-1-}$ mouse (lower); note the decrease in thioflavin signal in the sample from a 5xFAD/FAAH ${ }^{-/}$mouse. (B) Quantification of hippocampal amyloid plaques (thioflavin positive) revealeda significantly lower presence of these pathological structures in mice lacking FAAH. $A \beta_{1-40}$ and $A \beta_{1-42)}(D)$ levels are significantly lower in $5 x F A D / F A A H^{-/-}$mice. ${ }^{*} p<0.05$. Student $t$ test.

Figure 6: Representative western blots and quantification of amyloid-related proteins. (A) APP levels were increased in 5xFAD mice and significantly lower in FAAH-deleted mice. (B) BACE-1 protein was not modified either as a function of the pathological process or the genotype. (C) PS-1 protein was significantly higher in 5xFAD mice, but was not altered by FAAH genetic inactivation. ${ }^{*} \mathrm{p}<0.05$ (WT vs $5 x \mathrm{xAD}$ mice), $\#<0.05$ (5xFAD vs $5 x \mathrm{FAD} / \mathrm{FAAH}^{-/}$ mice). Two-way ANOVA followed by Bonferroni's post hoc test. 
Figure 7: 5xFAD/FAAH ${ }^{-/}$mice exhibit decreased astro-and micro-gliosis in the hippocampus. (A) Representative photographs of GFAP immunostaining of a 5xFAD mouse (left) and a 5xFAD/FAAH ${ }^{-/}$mouse (right). (B) Quantification of hippocampal GFAP+ cells showing significant increases as a consequence of the amyloid pathology as well as a significant decrease in $5 \mathrm{xFAD} / \mathrm{FAAH}^{-/}$as compared to 5xFAD. (C) Representative photomicrographs of a 5xFAD mouse (left) and a 5xFAD/FAAH ${ }^{-/}$mouse (right) and (D) quantification of hippocampal microgliosis (lba1+); note the significant increase as a consequence of the pathology and the decrease due to the genotype. (E) Representative pictures from a 5xFAD mouse (left) and a 5xFAD/FAAH ${ }^{-/}$mouse (right) of $\mathrm{CD} 68+$ cells: (F) densitometric quantification revealed no significant changes. Scale bar: $100 \mu \mathrm{m} .{ }^{*} \mathrm{p}<0.05$ (WT vs $5 x \mathrm{xAD}$ mice), \#<0.05 (5xFAD vs 5xFAD/FAAH ${ }^{-1}$ mice). Two-way ANOVA followed by Bonferroni's post hoc test.

Figure 8: Brain concentrations of FAAH-degraded NAEs are elevated in $\mathrm{FAAH}^{--}$and in URB-treated mice. Significant increases in AEA (A), PEA (B), and OEA (C), were found in the brains of $\mathrm{FAAH}^{-/-}$mice, as compared to WT mice. Importantly, concentrations of 2-AG remained unchanged (D). Note that no changes were observed due to the pathological process. ${ }^{*} p<0.05$. Oneway ANOVA followed by Tukey's post hoc test. 
Supplementary figure 1: Effects of the administration of URB or SR1 to WT and $\mathrm{FAAH}^{-/}$mice. IL1 $\beta(\mathbf{A}), \operatorname{IL} 6(\mathrm{~B}), \mathrm{TNF}_{\alpha}(\mathbf{C})$, and COX-2 (D) mRNA were not affected by the administration of any of both compounds, with the exception of the SR1 administration to $\mathrm{FAAH}^{-/-}$mice. iNOS mRNA levels (E) showed a different pattern, with a significant increase in SR1-treated WT mice. ${ }^{*} p<0.05$. One-way ANOVA followed by Tukey's post hoc test. 
Figure 1

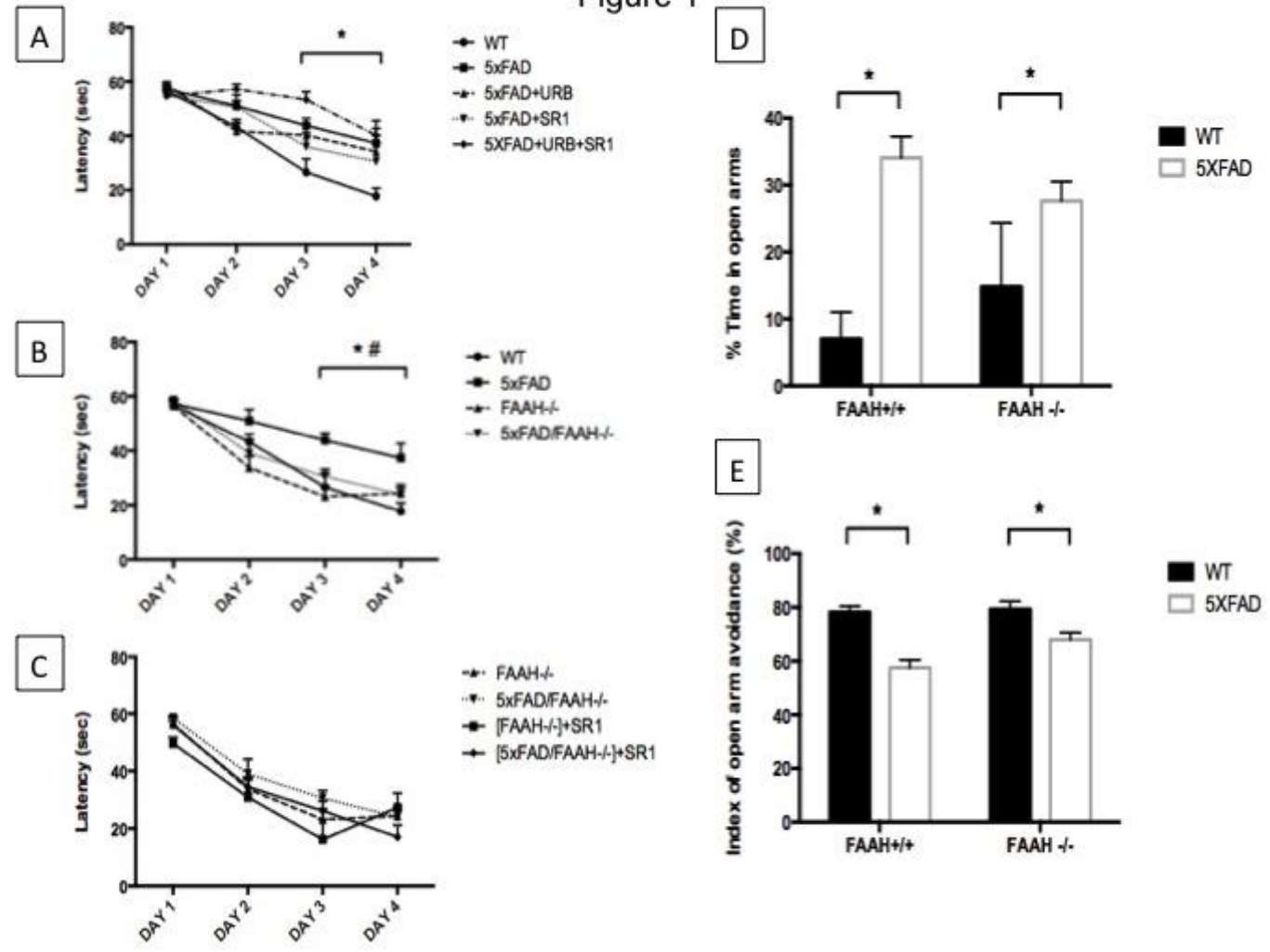


Figure 2

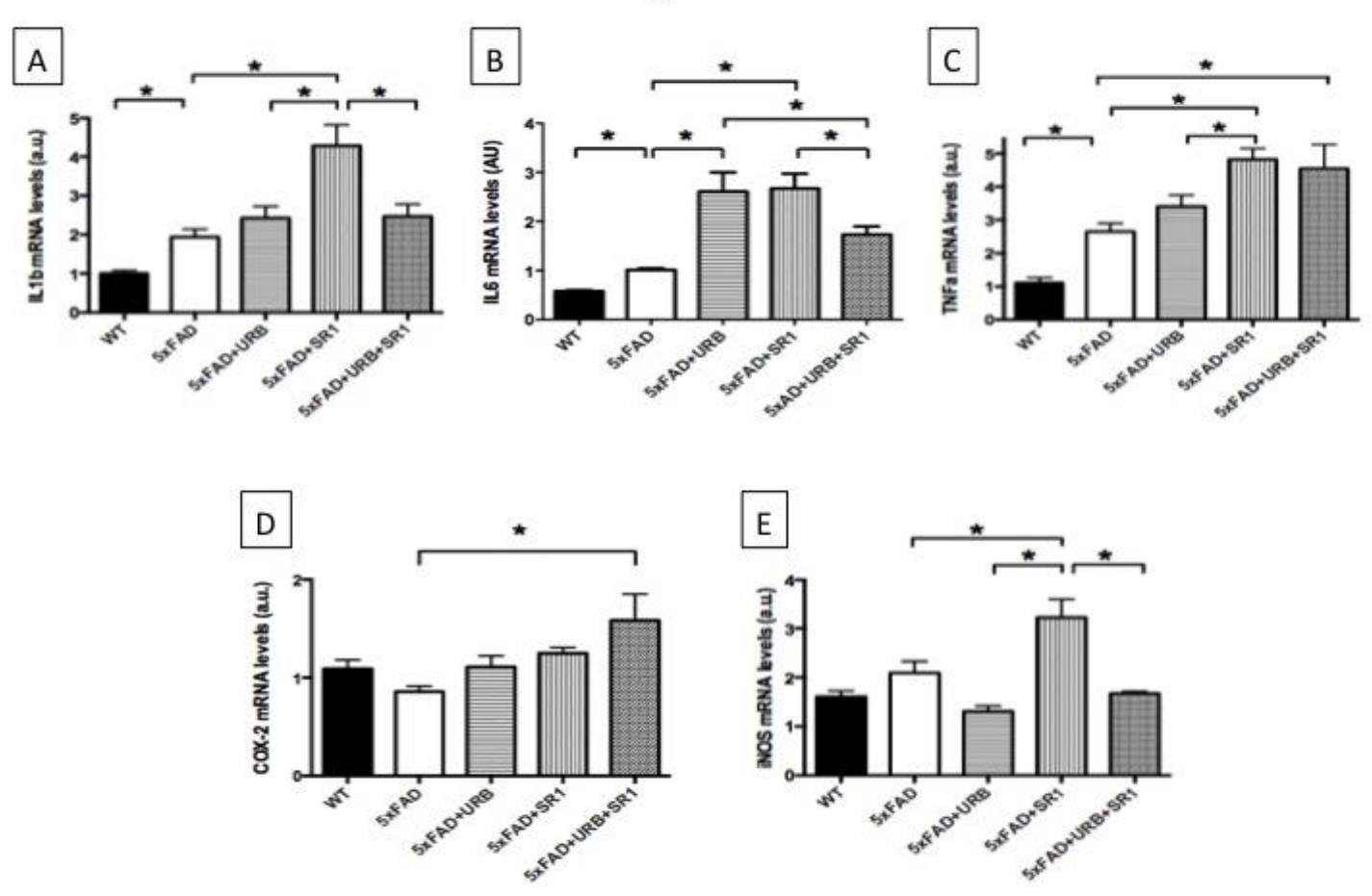


Figure 3

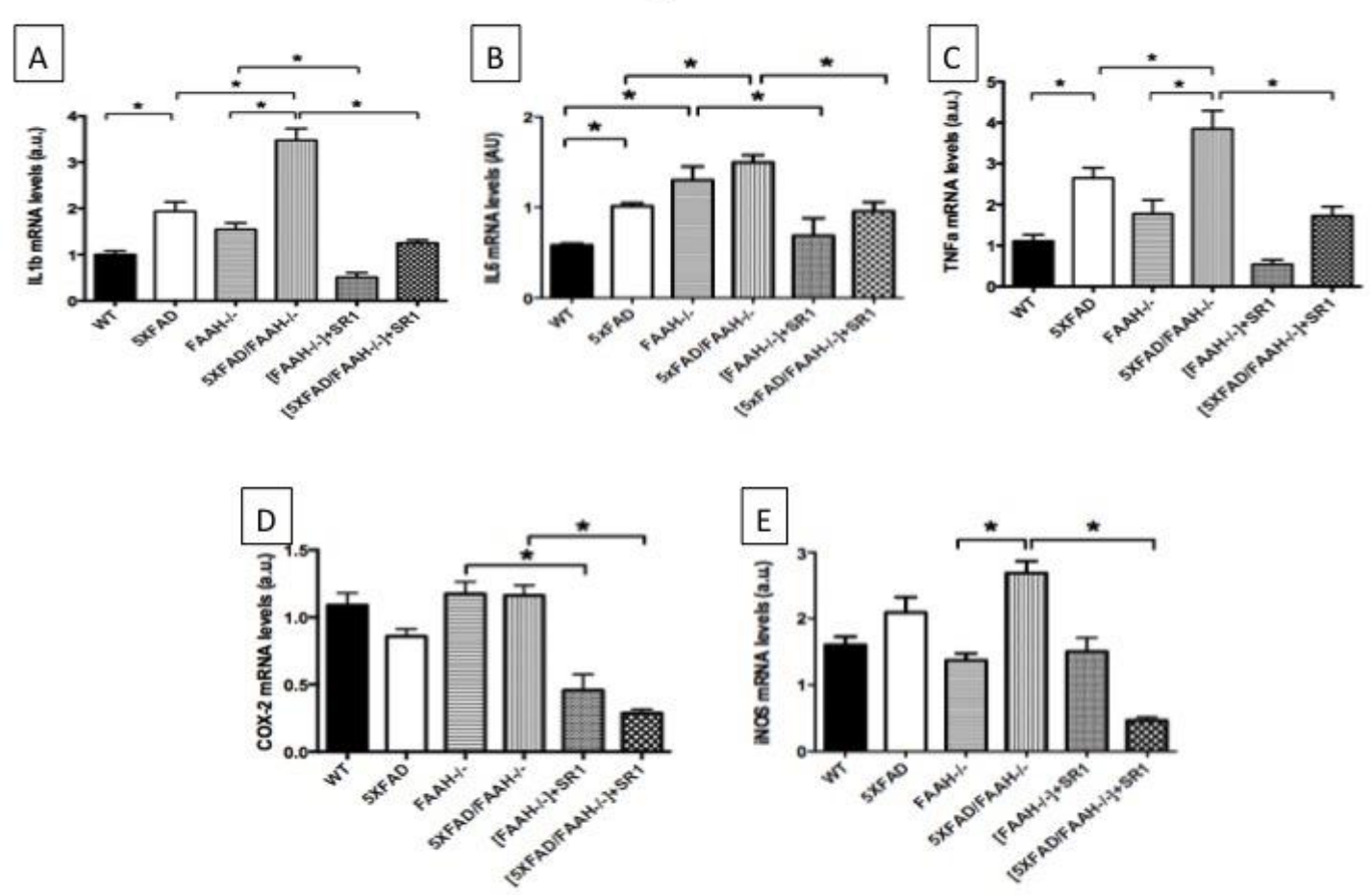


Figure 4

A

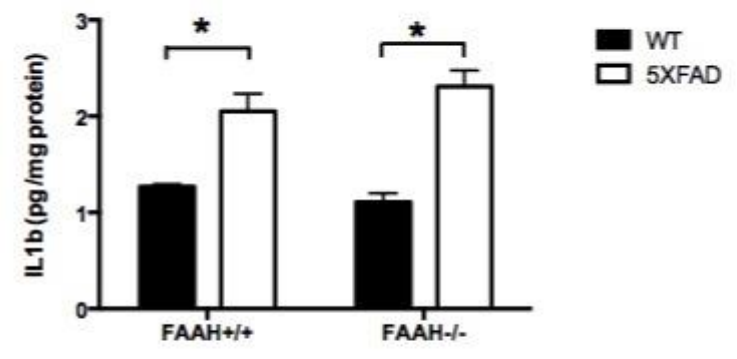

B

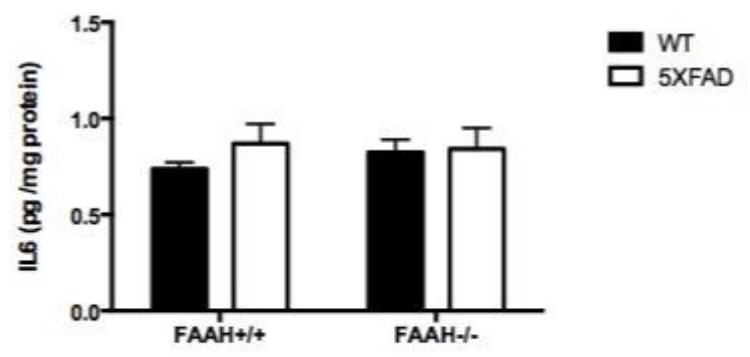


A

Figure 5
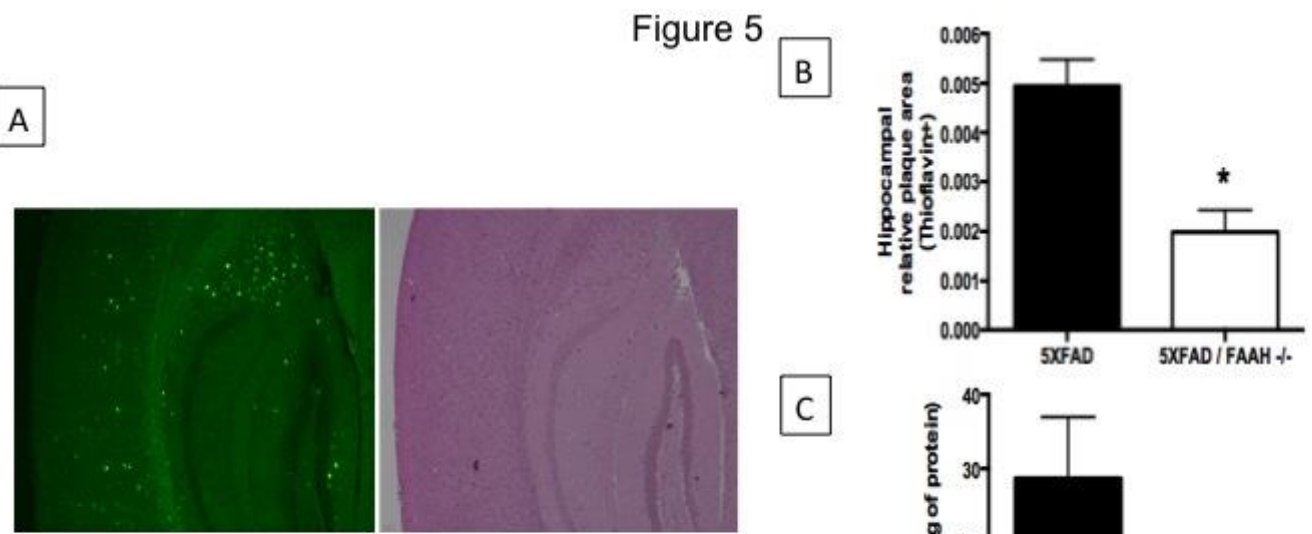

C

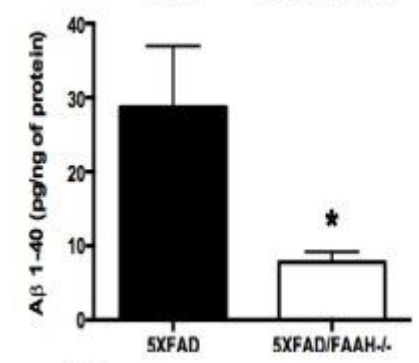

D

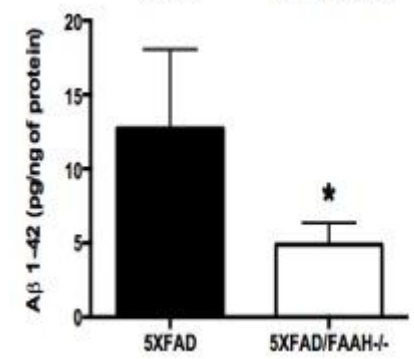


Figure 6

A
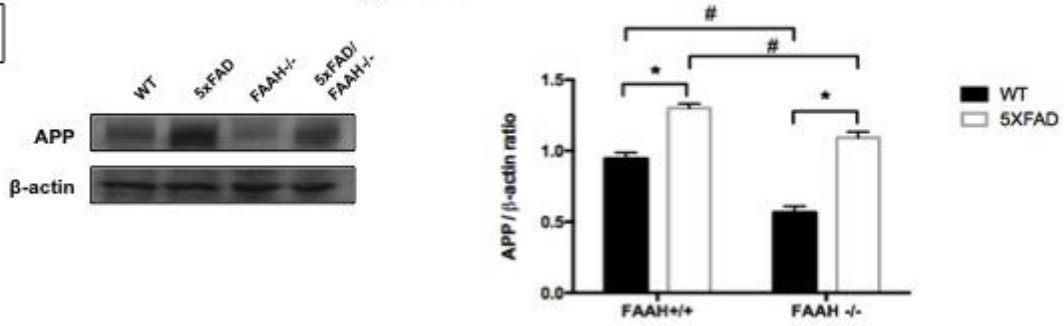

B
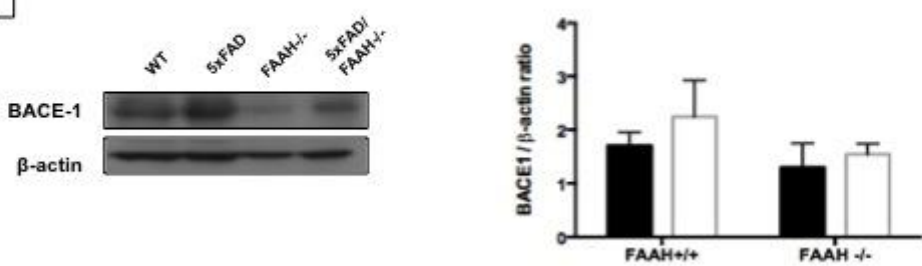

wr

C
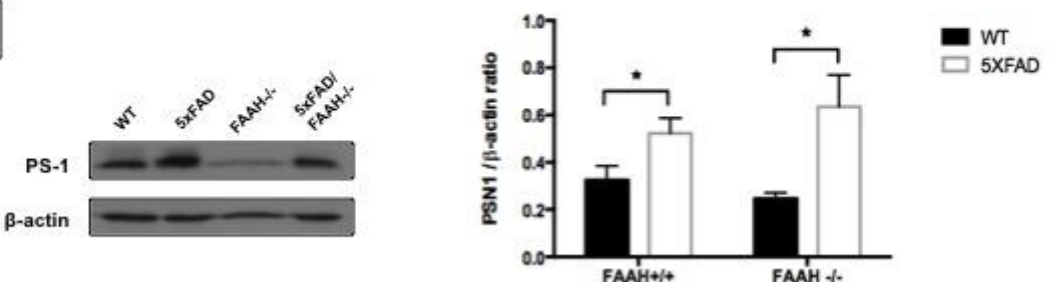
Figure 7

A

A $10 x+B$

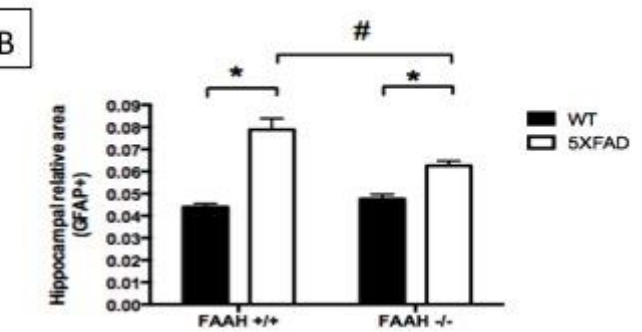

C

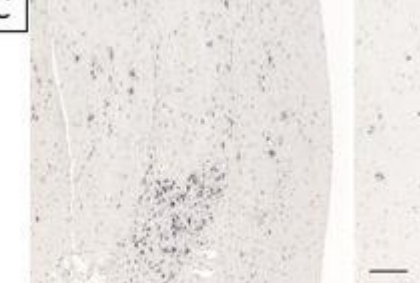

E

D

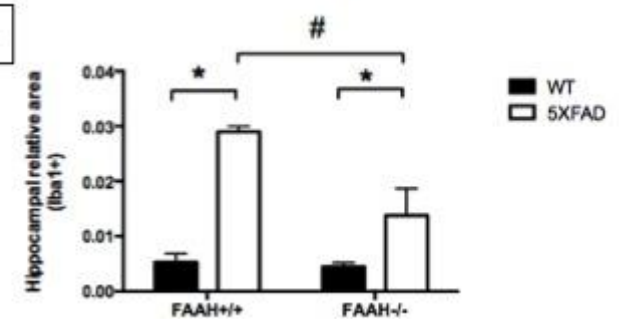

$\mathrm{F}$

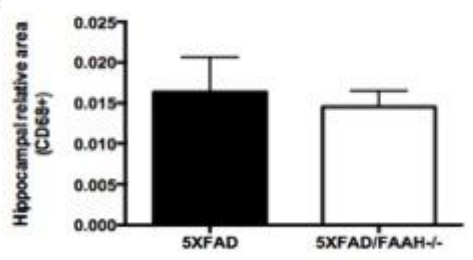


Figure 8
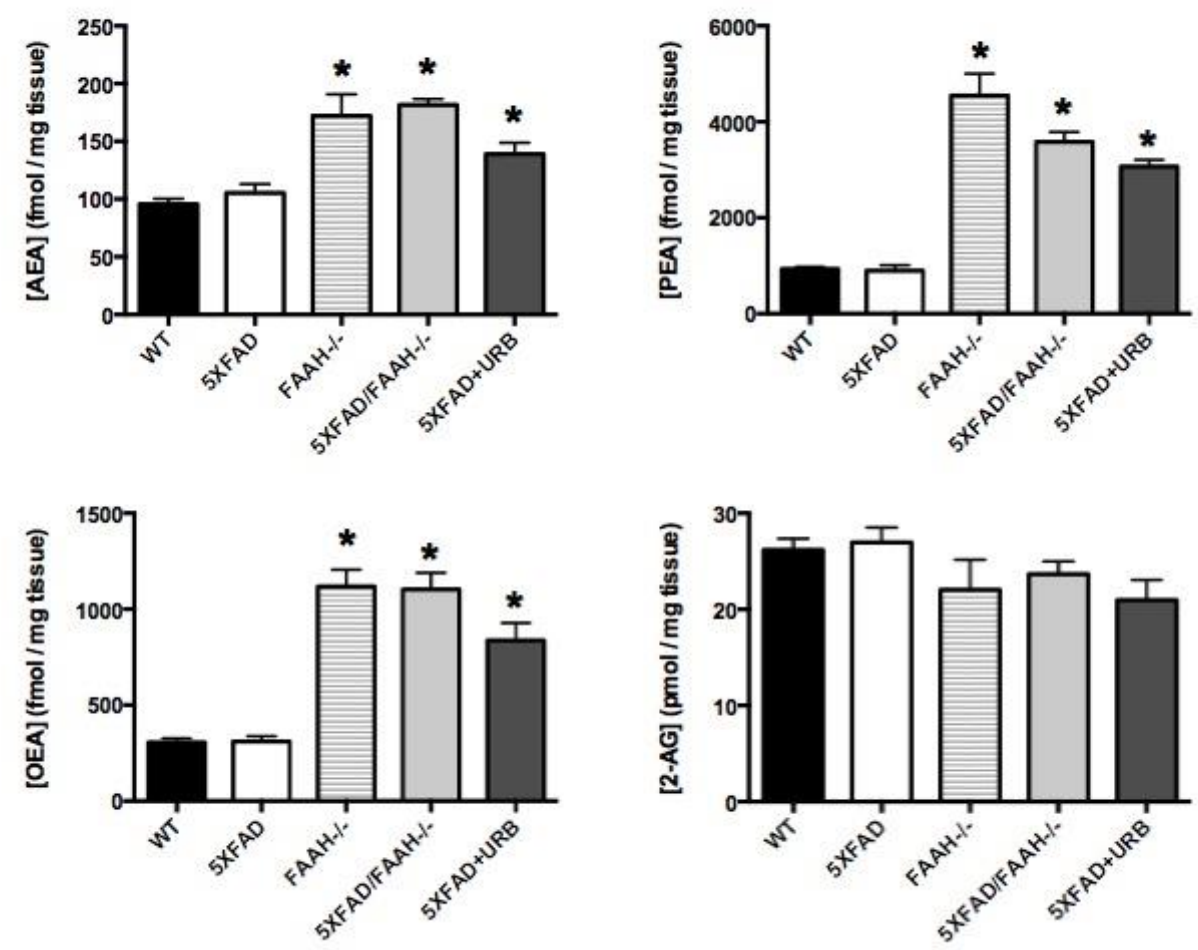
Supplementary Figure 1
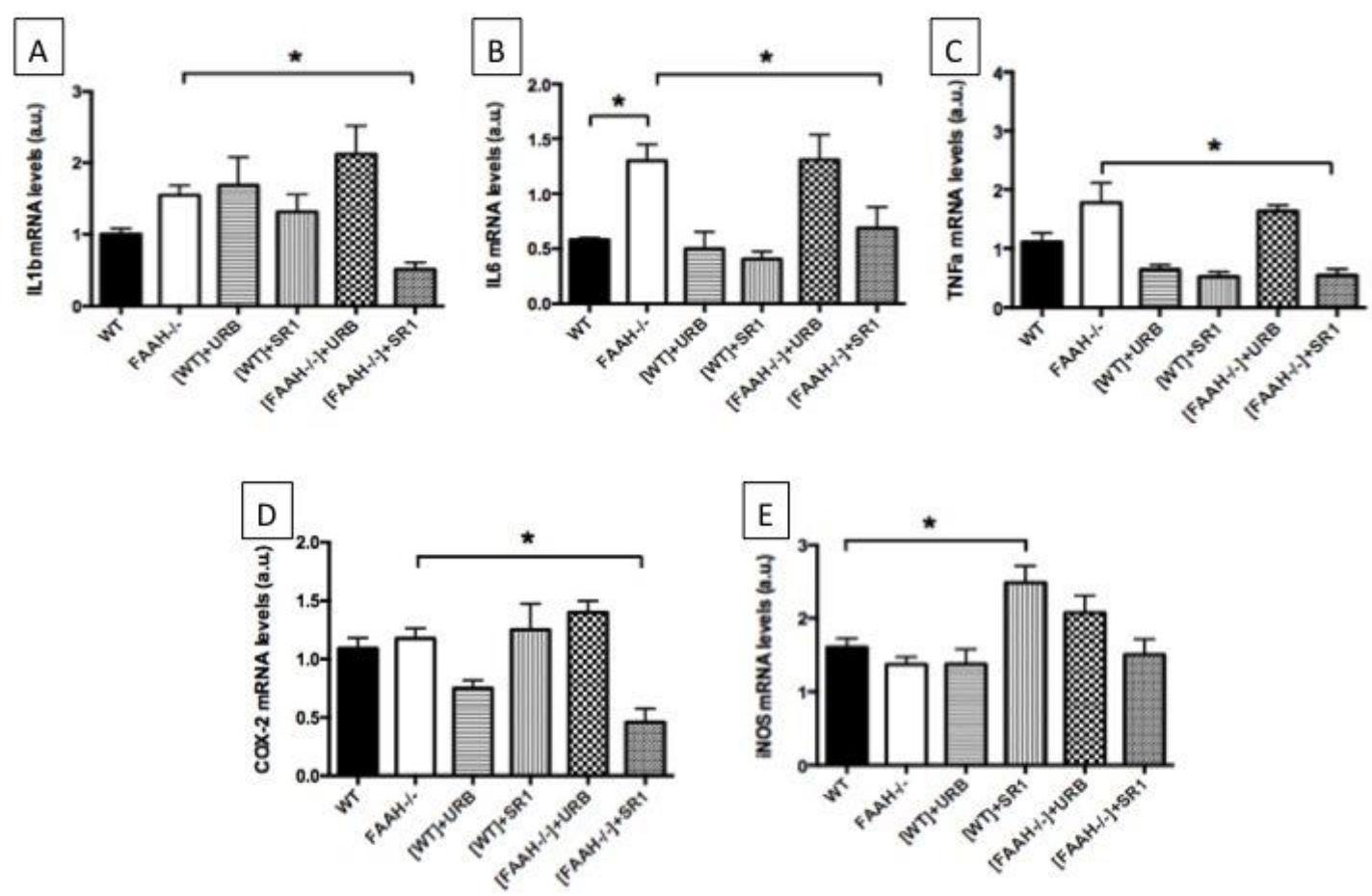